\title{
Electrochemical behaviour and corrosion sensitivity of prestressed steel in cement grout
}

\author{
E. Blactot ${ }^{1}$, C. Brunet-Vogel ${ }^{1}$, F. Farcas ${ }^{1}$, L. Gaillet ${ }^{1}$, I. Mabille ${ }^{2}$, \\ T. Chaussadent ${ }^{1} \&$ E. Sutter ${ }^{2}$ \\ ${ }^{1}$ Laboratoire Central des Ponts et Chaussées Paris, France \\ ${ }^{2}$ Ecole Nationale Supérieure de Chimie Paris, France
}

\begin{abstract}
The durability of prestressed concrete bridges primarily depends on the steel wire cables. Several disorders in these bridges are well known, such as fracture of these cables by stress corrosion cracking due to water penetration in the prestressing ducts. This water can contain various aggressive constituents with respect to corrosion (like chlorides). Its penetration inside the duct is due to the presence of sealing defects of the structure or in the concrete (like cracks). The second category of defects relates to the cement grout injection, which protects cables. This occurs due to a degradation of the grout in contact with water (problems of bleeding and segregation) leading to brittle fractures of steels. The first step of the study consisted in obtaining a corrosive liquid typical of a segregated cement paste on which electrochemical tests were done. Electrochemical tests in synthetic solutions defined from a bibliographical study and analysis of real cases of segregated cement grout were also realized. High strength and ordinary steel specimens were used and all the tests were mainly done in deaerated conditions. The main results can lead one to consider that, in oxygen free conditions, steel specimens surface can be either in active or passive state. The susceptibility of steels to stress corrosion cracking was determined by the means of models applied to potentiodynamic polarisation. Keywords: prestressed steel, corrosion, segregation, synthetic solution.
\end{abstract}

\section{Introduction}

In prestressed concrete structures, cement grout is injected in high-density polyethylene ducts containing the steel cables with the objective to ensure a 
protection against corrosion [1,2]. Nevertheless, under some particular conditions, this protection is not effective and could be sometimes the main initiator of steel passivation breakdown. Indeed, if the cement grout injection is badly carried out, it can exist bleeding, segregation, and even void zones $[3,4]$. These defects, far to be subjective, are an important concern for the concrete structure managers [5]. Solutions to avoid these types of defects exist but are used since relatively little time. So, for existing structures, cement grout heterogeneity could involve steel cable ruptures, which are the result of a stress corrosion phenomenon. Until now, the mechanisms of stress corrosion cracking (SCC) applied to this civil engineering case are not well known. The aim of this study is to evaluate the various parameters related on both the used materials and the environmental conditions, which can take part in these mechanisms.

\section{Origins of the corrosion initiation}

Protection conferred by cementitious materials to steel is well known. A passive layer is formed on the steel surface due to the high alkalinity, the quality of passive film however being able to be deteriorated by the presence of harmful species (chlorides, carbon dioxide). Within the framework of the present study, the characteristic of the corrosion phenomenon lies in the fact that the steel cables are under mechanical stress and that the surrounding medium is characterized by a bad cement grout, but also by the absence of oxygen in the ducts [6]. Heterogeneity of cement grout involves the presence of two different mediums: an healthy cement grout zone and a segregated cement grout zone, this last zone having the particularity to be strongly alkaline and to contain sulphate ions. Some of these zones are favourable to hydrogen formation (cathodic reaction), which can penetrate in the metal and weaken it. A stress corrosion cracking assisted by hydrogen can then occur and lead to the cable failure. Some other zones can be characterised by steel dissolution (anodic reaction) with loss of section.

Table 1: $\quad$ Chemical compositions of the studied steels (\%).

\begin{tabular}{|c|c|c|c|c|c|}
\hline & C & Mn & Si & P & S \\
\hline $\begin{array}{c}\text { Prestressing } \\
\text { steel }\end{array}$ & 0.81 & 0.68 & 0.23 & 0.01 & $<0.01$ \\
\hline $\begin{array}{c}\text { Reinforced } \\
\text { concrete steel }\end{array}$ & 0.04 & 0.44 & 0.12 & 0.02 & 0.04 \\
\hline
\end{tabular}

\section{Materials and experimental techniques}

\subsection{Materials}

Two commercial grade steel were used: a steel for prestressed concrete structure and an ordinary steel for reinforced concrete whose ultimate tensile strengths are respectively 1860 and $350 \mathrm{MPa}$. Their compositions are given in Table 1. 
They are both ferrito-pearlitic steels and the main difference between them is the carbon amount and microstructure. Prestressing steel has a fully-oriented microstructure related to the manufacture process (cold-drawing).

Before experiments, the surface preparation of the steels specimens was carried out using silicon carbide paper up to grade 1200. Specimens of prestressing steel were also studied without surface preparation as it is in real structures. In these conditions, the surface is covered by adherent products used to facilitate cold-drawing operation. In all cases, after polishing or not, the specimens were washed with distilled water, degreased with acetone and dried.

The studied mediums were defined in order to represent the characteristics of the segregated phase ( $\mathrm{pH}$ close to 14 and presence of sulphate ions). The behaviour of steel specimens was thus studied in three types of mediums: solution of $\mathrm{NaOH}$ ( $\mathrm{pH}$ range between 12 and 14), solutions of $\mathrm{NaOH}$ and $\mathrm{Na}_{2} \mathrm{SO}_{4}$ (same $\mathrm{pH}$ ) and segregated mediums (diluted or not) obtained by cement hydration under some conditions (additive to modify rheological characteristics of cement paste before hardening). The obtained segregated phase was composed of a liquid phase whose principal species are sulphate and hydroxyl ions and a white solid phase whose principal components are ettringite and portlandite. The compositions of the studied mediums are given in Table 2.

Within the framework of this study, all the solutions were deaerated before and during the tests by nitrogen bubbling.

Table 2: $\quad$ Compositions of the studied solutions.

\begin{tabular}{|c|c|c|}
\hline Studied environments & $\mathrm{SO}_{4}{ }^{2-}$ concentration $(\mathrm{mol} / \mathrm{L})$ & Measured $\mathrm{pH}$ \\
\hline $\mathrm{NaOH}$ & 0 & 13.6 \\
\hline $\mathrm{NaOH}+0.15 \mathrm{~g} / \mathrm{L} \mathrm{de} \mathrm{Na}_{2} \mathrm{SO}_{4}$ & $1.10^{-3}$ & 13.7 \\
\hline $\mathrm{NaOH}+15 \mathrm{~g} / \mathrm{L} \mathrm{de} \mathrm{Na}_{2} \mathrm{SO}_{4}$ & 0.1 & 13.6 \\
\hline $\mathrm{NaOH}+150 \mathrm{~g} / \mathrm{L}$ de $\mathrm{Na}_{2} \mathrm{SO}_{4}$ & 1 & 13.6 \\
\hline $\mathrm{Segregated} \mathrm{medium}$ & $1.85 .10^{-3}$ & 13.7 \\
\hline Diluted segregated medium & $1.85 .10^{-3}$ & 13.2 \\
\hline
\end{tabular}

\subsection{Experimental techniques and models}

In order to determine if steel is sensitive or not to stress corrosion in a considering environment, several methods can be used:

- Tests with an applied stress in the considering environment and by following steel evolution (mechanical and/or electrochemical properties) with time until its possible rupture.

- Tests without mechanical stress by plotting potential curves and applying predictive methods allowing one to determine the sensitivity of the steel to stress corrosion $[7,8]$. This last test type was considered within the present study.

The steel failure by stress corrosion cracking (SCC) is related to the coexistence of anodic and cathodic processes, which locally lead respectively to the metal dissolution and the hydrogen penetration into the material makes. 
The stress corrosion range in the anodic zone reveals the domain in which is likely to occur a reaction of localised dissolution on the steel surface. This phenomenon corresponds to the anodic mode of stress corrosion. In the majority cases of SCC, anodic dissolution is not the only cause but it is a necessary factor [9]. On the other hand, for cathodic potentials, when water dissociation becomes possible, a release of hydrogen can occur [9]. Thus, this range of potentials presents the risk of hydrogen embrittlement or hydrogen induced stress corrosion cracking (HISCC). The determination of the range of critical potential for which SCC occurs can be done using the potential curves. This exploitation makes it possible to confirm the role played by the active/passive transition in the cracking mechanism. To evaluate the sensitivity to SCC of the studied steels, potential curves were plotted at three different scanning rates: $0.25 ; 20$ and 83.3 $\mathrm{mV} / \mathrm{s}$. These various speeds allow one to apply two predictive methods (that of Parkins [7] and that of Fang and Staehle [8]) based on the current intensity measurements according to the potential scanning and then on calculations.

Parkins [7] defined a method being able to predict SCC susceptibility. This method leads to determine the range of potential in which this susceptibility could exist. Method developed by Parkins is based on potential curve plotted with high and low potential scanning rates.

According to Parkins, the conditions involving a stress corrosion phenomenon are met if the following points are respected:

- In the case of high potential scanning curve, current densities must be higher than $1 \mathrm{~mA} / \mathrm{cm}^{2}$

- The current density difference, at a given potential, between the high and low potential scanning rates, $\Delta \mathrm{I}$, divided by the current density corresponding to the slow scanning rate must exceed 1000 .

$$
\left(\mathbf{J}_{\text {high }}-\mathbf{J}_{\text {low }}\right) / \mathbf{J}_{\text {low }}>1000
$$

However, various researcher works [10,11] showed that a threshold of 100 was enough to determine if the steel is sensitive or not to stress corrosion.

Interest of this method resides in the fact that it allows to identify, on the potential curve, the active/passive transitions for a studied steel in a considered environment and consequently the potential range where the sensitivity of steel to stress corrosion is maximum.

Fang and Staehle's method [8] is based on the determination of a "stress corrosion cracking" parameter, noted $\mathrm{P}_{\mathrm{SCC}}$. This parameter is defined as a ratio between current densities obtained at high and low potential scanning rates for a given potential:

$$
\mathbf{P}_{\mathrm{scc}}(\mathbf{E})=\left(\mathrm{J}(\mathbf{E})_{20 \mathrm{mV} / \mathrm{s}}\right)^{2 / J}(\mathbf{E})_{0.2 \mathrm{mV} / \mathrm{s}}
$$

According to these authors, it is thus possible to correlate the value of the parameter $\mathrm{P}_{\mathrm{SCC}}$ with the susceptibility of steel to SCC: More the value of $\mathrm{P}_{\mathrm{SCC}}$ is high, more the susceptibility of steel to SCC is important. 


\section{Results and interpretation}

\subsection{Description of electrochemical conditions}

A preliminary study was realized to analyze electrochemical conditions of steel, when it is in contact with two different mediums: one defined by healthy cement paste and the other by a segregated state. The formation of these two mediums was naturally obtained by using cement (CEM I in the present study) and a suitable plasticizing additive. The measured potentials show the formation of an electrochemical cell in the considered cases $(\Delta \mathrm{V} \approx 150 \mathrm{mV}$ for the first two months). Consequently, an electrochemical phenomenon exists and is able to involve corrosion in the long term. The output intensity decrease with time varying from about $\mu \mathrm{A}$ (10 to 29$)$ to $\mathrm{nA}$ (70) after few months.

\subsection{Open circuit potential}

The open circuit potential measurements were realized in the different mediums. The obtained values depend on several parameters, and notably on surface state of the studied steel. More the value of the potential is negative, more the surface is active in term of corrosion.

Two mains groups of values were observed:

- $\quad \mathbf{- 3 0 0} \mathbf{m V}$ sce $<\mathrm{E}_{\text {cor }}<\mathbf{- 5 0 0} \mathbf{m} \mathrm{V}_{\text {sce, }}$, passive surface state

- $\quad \mathbf{- 6 0 0 ~} \mathbf{m V} V_{\text {sce }}<\mathrm{E}_{\text {cor }}<\mathbf{- 1 2 0 0 ~} \mathbf{m V}$ sce, active surface state

These two groups of corrosion potential values and the corresponding steel surface activity are given using potential curves (see 4.3).

The corrosion potentials values thus inform about the surface quality of studied steel. The steel will be more sensitive to corrosion phenomenon if its surface state corresponds to an active state.

The various corrosion potential measurements led to the same results distributed in a random way in the two groups of values, and this whatever the nature of steel and the composition of the solution. It can be noted that the corrosion potentials do not depend on the concentration of sulphate ions.

\subsection{Determination of SCC susceptibility}

Segregated zones of a badly cast cement paste are very alkaline and contain high amount of sulphate ions. For a better understanding of sulphate amounts and $\mathrm{pH}$ influences, potential curves at several potential scanning rates in real segregated mediums or synthetic solutions (Table 2) were plotted and analyzed.

\subsubsection{Influence of sulphate ions}

Tests were conducted to determine which could be the sulphate action on the electrochemical behaviour of the steel (for prestressing applications) according to the sulphate concentration at $\mathrm{pH} \approx 13.6$ (Figure 1).

When potential curves are plotted with high potential scanning rates, two anodic peaks are observed, one being located around $-1000 \mathrm{mV}_{\mathrm{SCE}}$, which could 
correspond to an intergranular stress corrosion and another around $-750 \mathrm{mV}_{\mathrm{SCE}}$ rather related to transgranular cracking according to [12].

Differences concerning the peak intensity can be considered as negligible, although there is a discrepancy of potentials. It can be admitted that in the case of a deaerated medium, at a high alkaline $\mathrm{pH}$, sulphate ions have little influence on active/passive transition, and that sulphate concentration in the medium play a negligible role.

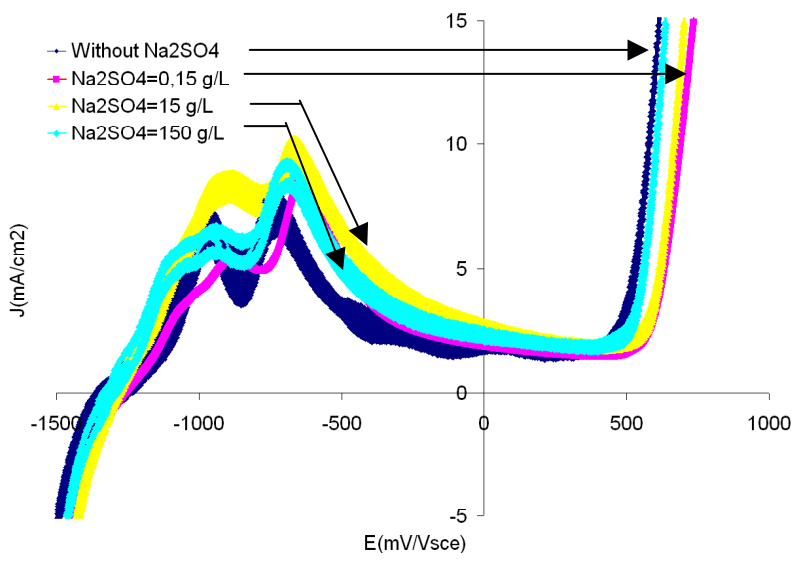

Figure 1: Influence of sulphate content on the potential curves - Raw prestressing steel (Scanning rate $=83.3 \mathrm{mV} / \mathrm{s}$ ).

\subsubsection{Influence of $\mathrm{pH}$}

As it can be seen on Figure 2, which collected potential curves at different $\mathrm{pH}$ in different mediums, it seems that the behaviour of prestressing steel strongly depends on the $\mathrm{pH}$ :

- When the steel is in contact with a solution whose $\mathrm{pH}$ is about 13.6, two distinct anodic peaks are observed:

- The first one is at a potential of $-1000 \mathrm{mV}_{\text {sce }}$

- The second one at a potential of $-750 \mathrm{mV}_{\text {sce }}$

- When the steel is in contact with a solution whose $\mathrm{pH}$ is about 12.9:

- Only one peak is observed, much less intense than at $\mathrm{pH} 13.6$, locating at a potential around $-520 \mathrm{mV}_{\text {sce }}$,

- Peaks are followed by a pseudo passivation stage extending up to +500 $\mathrm{mV}_{\mathrm{SCE}}$ at $\mathrm{pH}$ 13.6. At $\mathrm{pH} 12.9$ and in a diluted segregated medium, the length of this stage is more important, the transpassivation potential locating at $+800 \mathrm{mV}_{\mathrm{SCE}}$. The increase of current in the transpassivation zone can be assigned to the oxidation of water.

- When the prestressing steel is in a diluted segregated medium at $\mathrm{pH}=13.2$, its behaviour is similar to that of the prestressing steel at $\mathrm{pH}=12.9$. 


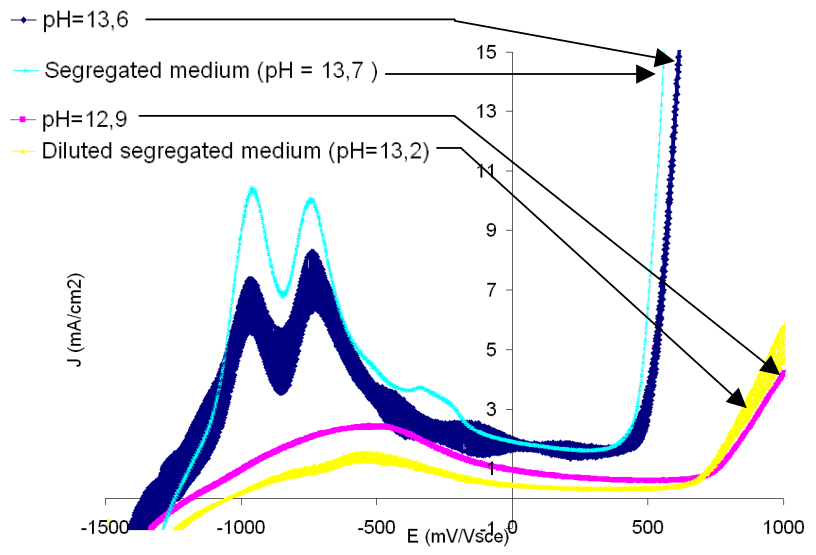

Figure 2: Influence of $\mathrm{pH}$ on the potential curves Raw prestressing steel (Scanning rate $=83.3 \mathrm{mV} / \mathrm{s}$ ).

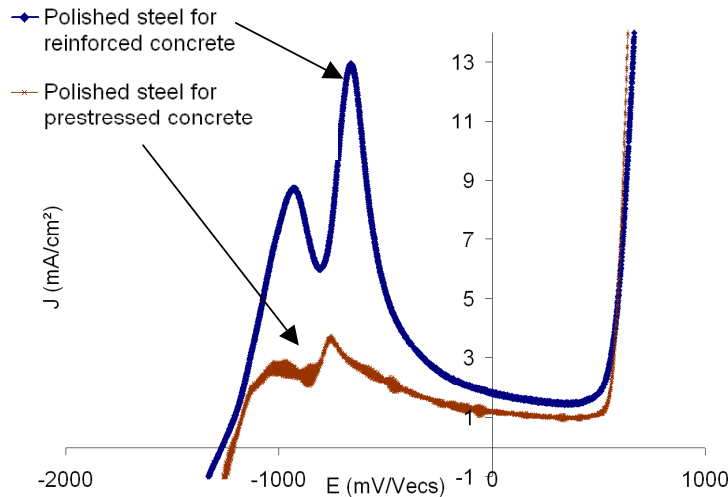

Figure 3: Electrochemical behaviour of polished prestressing steel and reinforced cement steel $(\mathrm{pH}=13.6$ - Scanning rate $=83.3 \mathrm{mV} / \mathrm{s})$.

These observations confirm the important influence of the $\mathrm{pH}$. In the case of low alkalinity $(\mathrm{pH}=12.9)$, corrosion risks are lower: the oxidation peak is less intense, which correspond to a best aptitude to passivity. It can be observed the same electrochemical behaviour for steel in diluted segregated medium $(\mathrm{pH}=$ 13.2). An increase of $\mathrm{pH}$ to 13.7 leads to a more important sensitivity of steel to $\mathrm{SCC}$, considering that potential curves at low potential scanning rate are almost identical for the different $\mathrm{pH}$ studied.

\subsubsection{Influence of steel characteristics}

To analyze the influence of the different steels (polished reinforced concrete steel and polished prestressing steel), comparison of potential curves in high alkaline medium is presented in Figure 3. 
Heights of the peaks indicate that polished prestressing steel presents a better aptitude to passivation than the polished reinforced concrete steel. This fact can be explained by carbon amount (studies showed that low carbon steel is very sensitive to corrosion in high alkalinity medium [13]) that leads to different microstructure.

The non-polished prestressing steel presents at its surface a black layer, which is composed of residual products used for cold drawing. This layer seems to be partially destroyed (presence of strongly active and passive zones) during cathodic polarisation, which involves, as a consequence, an important surface reactivity (see Figure 4).

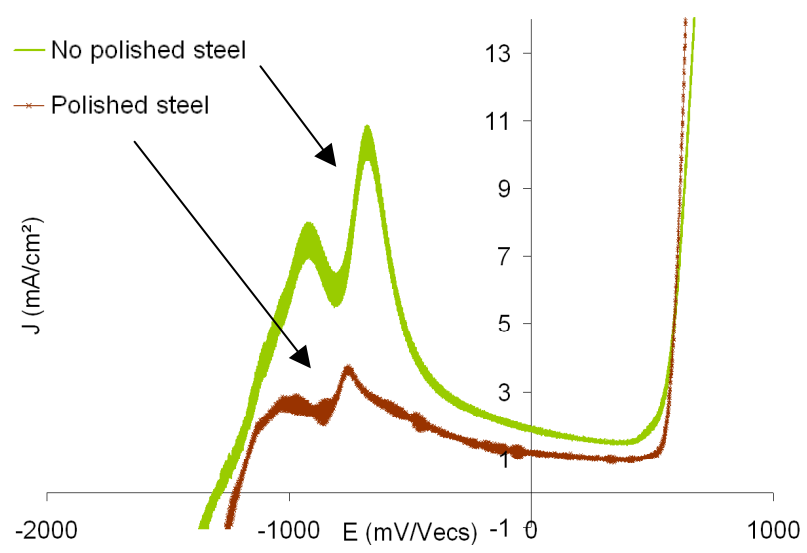

Figure 4: Electrochemical behaviour of polished or not prestressing steel ( $\mathrm{pH}$ $=13.6-$ Scanning rate $=83.3 \mathrm{mV} / \mathrm{s}$ ).

Table 3: Determination of the susceptibility of steels to SCC using predictive methods.

\begin{tabular}{|c|c|c|}
\hline Steel & Parkins' method & $\begin{array}{c}\text { Fang et Staehle's } \\
\text { method }\left(\mathrm{P}_{\mathrm{scc}}\right)\end{array}$ \\
\hline $\begin{array}{c}\text { For concrete } \\
\text { reinforcement }\end{array}$ & 159 & 34 \\
\hline $\begin{array}{c}\text { For prestressing concrete } \\
\text { (polished surface) }\end{array}$ & 49 & 5 \\
\hline $\begin{array}{c}\text { For prestressing concrete } \\
\text { (non-polished surface) }\end{array}$ & 499 & 625 \\
\hline
\end{tabular}

These observations are supplemented by calculations based on the previously described methods of Parkins and Fang and Staehle. Results of calculations reported in Table 3 give some information for the susceptibility of the studied steels in a $\mathrm{NaOH}$ solution at $\mathrm{pH}$ 13.6. It can be noted that the low carbon steel is susceptible to SCC, which is in compliance with the literature [14]. The non- 
polished prestressing steel is very susceptible to SCC in a high alkalinity medium, this susceptibility being in connection with the presence of a specific layer on the surface. The mechanisms involved in such behaviour and their real influences on SCC are not known for the moment.

\section{Conclusions and prospects}

Prestressing steel in contact with segregated cement grout is subjected to SCC phenomena.

The tendency of prestressing steel to SCC is evaluated by analyzing the impact of potential scanning rates on potential curves (Parkins' and Fang and Staehle's methods). The range of potential for which steel is subject to SCC is thus determined (between -800 and $-600 \mathrm{mV}_{\text {sce }}$ ).

The experiments were carried out without mechanical stress and aimed to identify the influence on steel SCC susceptibility.

It can be concluded that:

- Sulphate content has a poor influence on SCC in theses conditions $(\mathrm{pH}>12)$.

- High $\mathrm{pH}$ can generate important anodic peaks in the zone of active/passive potential.

In addition, the study relating to the type of steel makes it possible to confirm the best resistance of the polished prestressed concrete steel to SCC in high alkalinity medium compared to the reinforced concrete steel. Moreover, it can be considered that a specific layer present on prestressing steel surface due to cold drawing process breaks up and thus generates a high susceptibility to corrosion.

The whole of these tests were carried out without mechanical stress, further works are in progress to analyse the influence of stress on SCC mechanisms by using the same types of solutions.

\section{References}

[1] FIP, French technique for prestressed concrete structures, $X I^{e}$ congress, Hambourg, 1990.

[2] Ministère de l'aménagement du territoire, de l'équipement, du logement et du tourisme, Directive provisoire sur les injections des gaines des ouvrages en béton précontraint, mars 1973 (in French).

[3] US Department of transportation, Performance of Grouts for PostTensioned Bridge Structures, Publication No FHWA-RD-92-095, December 1993.

[4] Ganz, H.R., Vildaer, S. Grouting of post- tensioning tendons. VSL International LTD, May 2002.

[5] FIP commission on prestressing materials and systems, Collection of monographs on premature fracture of prestressing reinforcement used in prestressed concrete structures or products and for other purposes, second edition, march 1990.

[6] Nürnberger, U. Corrosion induced failures of prestressing steel. OttoGraf-Journal, 13, pp. 9-25, 2002. 
[7] Parkins, R.N. Predictive approaches to stress corrosion cracking failure Corrosion Science 20, pp.147-166, 1980.

[8] Fang, Z. \& Staehle, R. W., Effects of the valence of sulfur on passivation of alloys 600,690 , and 800 at $25^{\circ} \mathrm{C}$ and $95^{\circ} \mathrm{C}$. Corrosion 55 (4), pp. 355 379, 1999.

[9] Desjardin, D., Oltra R. (1990) Corrosion sous contrainte: Phénoménologie et mécanismes. Les éditions de Physique - Bombannes, Paris, 1990 (in French)

[10] Alonso, M.C. \& Andrade, M.C. The electrochemical behaviour of steel reinforcements in $\mathrm{Na}_{2} \mathrm{CO}_{3}$ and $\mathrm{NaHCO}_{3}$ solutions in relation to stress corrosion cracking. Corrosion Science, 29 (9), pp 1129-1139, 1989.

[11] Alonso, M.C., Procter, R.P.M., Andrade, C. \& Saenz de Santa Maria, M., Susceptibility to stress corrosion cracking of a prestressing steel in $\mathrm{NaHCO}_{3}$ solutions, Corrosion Science 34 (6), pp 961-973, 1993.

[12] Parkins, R.N. \& Zhou, S., The stress corrosion cracking of C - Mn steel in $\mathrm{CO}_{2}-\mathrm{HCO}_{3}^{-}-\mathrm{CO}_{3}{ }^{2-}$ solutions II: Electrochemical and other data, Corrosion Science 39(1), pp 175-191, 1997.

[13] Saxena, A., Singh Raman, R.K. \& Muddle, B.C., Slow strain rate testing for monitoring cracking of mild steels for vessels and pipes for processing using caustic solutions. Pressure Vessels and Piping, 83, pp 399-404, 2006.

[14] Rihan, R.O. \& Nesic, S., Erosion - Corrosion of mild steel in hot caustic Part I: NaOH solution. Corrosion Science 48 (9), pp 2633-2659, 2006. 